Acta Univ. Sapientiae, Economics and Business, 3 (2015) 5-26

DOI: 10.1515/auseb-2015-0001

\title{
A Causal Model of Consumer-Based Brand Equity
}

\author{
Attila SZŐCS \\ Sapientia Hungarian University of Transylvania, Faculty of Economic and Human \\ Sciences Department of Business Sciences, Miercurea Ciuc \\ e-mail: szocsattila@sapientia.siculorum.ro \\ József BERÁCS \\ Kecskemét College, Faculty of Mechanical Engineering and \\ Automation, Kecskemét
}

\begin{abstract}
Branding literature suggests that consumer-based brand equity (CBBE) is a multidimensional construct. Starting from this approach and developing a conceptual multidimensional model, this study finds that CBBE can be best modelled with a two-dimensional structure and claims that it achieves this result by choosing the theoretically based causal specification. On the contrary, with reflective specification, one will be able to fit almost any valid construct because of the halo effect and common method bias. In the final model, Trust (in quality) and Advantage are causing the secondorder Brand Equity. The two-dimensional brand equity is an intuitive model easy to interpret and easy to measure, which thus may be a much more attractive means for the management as well.
\end{abstract}

Keywords: brand equity, structural equation modelling, causal measurement models

JEL Classification: C3,M31

\section{Introduction}

The present paper focuses on measuring consumer-based brand equity defined by Aaker (1991) as a set of brand assets or liabilities that add to or subtract from the value provided by a product or service. The empirical research based on Aaker's (1991) model has significantly determined the approach of the present paper.

The concept of brand equity became popular at the beginning of the eighties mainly as an agency-based measure of marketing efficiency (Interbrand, Coopers and Lybrand, Arthur Young Australia). After the conference of the Marketing Science Institute in 1988, the concept gained quick academic acceptance (Farquhar, 1989; Aaker 1991, 1993; Keller, 1993). 
Consumer-based brand equity research predominantly uses structural equations for estimation (Erdem \& Swait, 1998; Yoo \& Donthu, 2000; Vázquez et al., 2002; Netemeyer et al., 2004; Martensen \& Gronholdt, 2004; Erdem et al., 2006; Jensen \& Klastrup, 2008; Chau \& Ho, 2008; Boo et al., 2009; Atilgan et al., 2009; Kim \& Hyun, 2010). Some studies do not operationalize brand equity but only its dimensions (Vázquez et al., 2002; Boo et al., 2009; Netemeyer et al., 2004), while others do not estimate brand equity as a second-order latent variable, but they include the construct as a dependent variable (Martensen \& Gronholdt, 2004; Kim \& Hyun, 2010). Some studies estimate the causal measurement model in isolation and do not report on appropriate fit indicators (Martensen \& Gronholdt, 2004). Atilgan et al. (2009) operationalize brand equity as a latent variable, but they estimate only the CFA (Confirmatory Factor Analysis) model and do not provide information about structural relationships (but they do provide the cultural validation of their model). In general, no author argues about the reflective, respectively the formative or causal specification they choose in designing their consumer-based brand equity model. This could be attributed to the fact that the academic debate on causal vs. reflective specification is relatively new.

Several empirical models employ the causal specification of consumerbased brand equity without arguing about the chosen specification. Martensen and Gronholdt (2004) specify consumer-based brand equity in a causal measurement model; however, they do not provide parameter results and goodness-of-fit indices of estimation, and they estimate the model in PLS (Partial Least Square), similarly to Jensen and Klastrup (2008), who develop their model for business to business markets. Baldauf et al. (2009) specify brand equity as a second-order construct, but they measure brand equity on the level of retailers. This study estimates a second-order factor model in covariancebased SEM (Structural Equation Model - Amos), while the significant majority of the studies estimate second-order factor models in PLS as Diamantopoulos, Riefler, and Roth (2008) present them.

Keller's conceptual models $(1993,2003)$ and the articles by Lehman et al. (2008), Vazquez et al. (2002), and Martensen and Gronholdt (2004) suggest that consumer-based brand equity is a multidimensional concept. Lehman et al.'s (2008) article measures 27 concepts, and then reduces them to six factors; Vazques et al. (2002) suggest 8, Martensen and Gornholdt (2004) and Keller (2003) suggest 6 dimensions.

The initial model of this paper is based on the conceptual model of Aaker $(1991,1993)$ as other important brand equity models; therefore, our model shows similarities to these empirical models, especially to the Yoo and Donthu (2000) model. Our model differs from the other empirical models as it tries to overcome the listed shortcomings; it concretely differs from the Yoo and Donthu (2000) model in specifying brand equity as a second-order latent variable, and models 
its consequences. An important characteristic of our model is that we estimate it in a covariance-based SEM, not in the more convenient PLS.

The remainder of this paper is structured as follows. The next section presents the initial model of this study, the third section deals with the specificationrelated questions of our model, section four presents the methodology employed, section five presents the results, and section six discusses.

\section{The Initial Second-Order Model of Consumer-Based Brand Equity}

This study re-interprets the consumer-based brand equity concept by asking the question which are those brand-related concepts that can enter an associative structure where they are simultaneously influencing (causing) something.

The study modifies the initial structure of the Aaker (1991) model after reevaluating the empirical studies based on Aaker's (1991) conceptual model and the multidimensional character of Keller's (1993) conceptual model. The conceptual development of the consumer-based brand equity model of this paper differs from the empirical models based on Aaker's (1991) model in some important points. This study does not define brand-related associations as one concept but includes associations as separate concepts (Uniqueness, Trust, etc.), thus making possible a more detailed assessment of brand-related associations. Further on, the study includes in the model as specific associations the dimensions of differentiation (Advantage and Uniqueness). In spite of the theoretical importance attributed to it (Aaker, 1996; the American Marketing Association's definition of brand; Bauer \& Berács, 2006), apart from a few exceptions (Martensen \& Gronholdt, 2004; Young and Rubicam's Brand Asset Valuator), differentiation is not present in CBBE models.

The present model endeavours to take into account the business reality that changes as a consequence of the economic crisis and the spreading of social networks, and it includes the dimension of trust in the initial model. Trust has become an essential factor due to the increasing consumer consciousness, availability of quality-related information; on the other hand, the signalling theory states that the success of brand building significantly depends on the extent to which consumers trust the communication of a brand (Erdem \& Swait, 1998).

The empirical research (Yoo \& Donthu, 2000; Washburn \& Planck, 2002; Chau \& Ho, 2008; Atilgan et al., 2009; Kim \& Hyun, 2010) includes four components of the Aaker (1991) model, namely: Perceived Quality, Loyalty, Awareness, and Associations.

Unlike earlier practice, this study interprets Loyalty similarly to Erdem and Swait (1998), as the consequence of brand equity. To measure Loyalty, following the direction Aaker (1996) indicates, the study uses scale items explicitly referring 
to purchase decisions. In the case of such operationalization of loyalty though, the authors do not find it acceptable that Loyalty explains, through its effect on Brand Equity, a consequence of Brand Equity such as Purchase Intention.

The study reinterprets the three Aaker dimensions, following Aaker's (1996) instructions, among others, as follows. Awareness concretely refers to the brand node existing in the consumer's mind; every other brand-related concept qualifies as an association, and since everything that connects with some strength to a brand name representing the node in the association network is an association (Keller 1993).

Consequently, the conceptual model of this study incorporates Awareness and brand-name-related associations such as Uniqueness, Advantage, Perceived Quality, Activity, and Trust.

The following sections present in detail the hypothesized dimensions of the initial model.

\subsection{Awareness}

Consumers are more likely to select well-known brands from the consideration set (Hoyer \& Brown, 1990; Leong 1993), and the consumers who choose a brand with high awareness consider fewer alternatives and more rarely choose the best quality brands (Hoyer \& Brown, 1990). The results of the classical articles of Hoyer (1984) and Hoyer and Brown (1990) were repeatable on other, greater samples (MacDonald \& Sharp, 2000; Huang \& Sarigöllü, 2012), and Leong (1993) confirms their cultural validity. The awareness dimension does not enter the final model in some cases (Atilgan et al., 2009) nor does this dimension fit as an independent one (Yoo \& Donthu, 2001; Kim \& Hyun, 2010), and from the analysed thirteen empirical models only one accepts awareness as an independent dimension of the final model (Boo et al., 2009). Given the importance of awareness in the conceptual models (Aaker, 1991; Keller, 1993), the authors still consider it important to introduce awareness into the initial model to find out how this dimension fits the causal structure of the model.

\subsection{Uniqueness}

This study operationalizes uniqueness and advantage as the subdimensions of a more comprehensive differentiation. Differentiation means that a brand is able to provide more in the case of a certain characteristic than a concurrent one in such a way that consumers' sensitivity and expectation towards other characteristics decrease, due to which a brand can reduce costs (Sharp \& Dawes, 2001). Uniqueness measures merely distinctness since there are consumers who, to enhance their consumer status, distinguish themselves from others by possessing a brand. 


\subsection{Advantage}

The advantage dimension measures the extent to which a brand can differentiate itself in such a way that it offers real benefits compared to its competitors. The advantage dimension is part of the agency-based BrandZ model and it is also a dimension of the second-order comparative advantage in the brand performance model (Lehman et al., 2008).

The operationalization of Advantage makes this dimension similar to the conceptualization of the perceived value that Zeithalm (1988) formulates as "value is whatever I want in a product".

\subsection{Perceived Quality}

Perceived quality is one of the key dimensions of consumer-based brand equity (Aaker, 1996; Netemeyer et al., 2004); it is present in a great number of consumerbased brand equity models (Yoo\&Donthu, 2001; Netemeyer et al., 2003; Erdem \& Swait, 1998; Erdem et al., 2006; Atilgan et al., 2009; Boo et al., 2009; Kim \& Hyun, 2010) and constitutes the dimension of Aaker's (1991) conceptual brand equity model.

Perceived quality adds value to the product by creating motivation to buy, making price premium application possible, and differentiating the brand. Companies characterized by high market orientation invest in quality development instead of trying to achieve a better financial performance with price cuts (Hooley et al., 2000). The research of Jacobson and Aaker (1987) on 3,000 strategic business units from PIMS database finds perceived quality the most important factor influencing returns. Managers indicated perceived quality as the most important source of competitive advantages (Aaker, 1989).

\subsection{Activity}

Social communities, through the spectacular spreading of community networks (Facebook, Twitter, etc.) and user-generated content (blog, forums), have a significant impact on judging brands and spreading brand-related information (Patterson, 2012), and they increase the instability of the market structure (Sengupta \& Greetham, 2010). In Peres et al. (2010), the re-definition of innovation diffusion is necessary to stress the central role of social relations in the innovation diffusion model. In the present, the initial model activity measures the consumers' willingness to share information about a brand, to treat it as part of their everyday life (Lehman et al., 2008). 


\subsection{Trust}

Trust is one of the most important concepts related to a brand (Delgado \& Munuera, 2005; Delgado et al., 2003; Chaudhuri \& Holbrook, 2001). Trust is a component of several consumer-based brand equity measures (Martensen \& Gronholdt, 2004; Christodoulides et al., 2006; Atilgan et al., 2009; Research International's Equity Engine). ${ }^{1}$ Trust is also a component of credibility that plays a central role in Erdem and Swait's (1998) and Erdem et al.'s (2006) CBBE model. When the number of accessible brands grows at a spectacular pace on the market and more low-quality products appear increasingly, trust in a brand is becoming one of the most important factors of consumer-based brand equity. Trust measures a brand's perceived ability to fulfil its offers; thus, a reliable brand does not necessarily provide high quality, but it provides the quality promises.

\subsection{Purchase Intention}

In the case of brands with high brand equity, this study expects higher willingness to purchase, assuming that high brand equity positively influences purchase intent (Laroche et al., 1996; Cobb-Walgreen et al., 1995; Christodoulides et al., 2006). In their meta-analysis of brand equity, Agarwal and Rao (1996) mark purchase intention as a brand equity measure of high priority, but they do not interpret it as a consequence of brand equity.

\subsection{Low Search Cost}

The economic literature discusses the reduced search costs as one of the most important advantages provided by a brand (Ramello, 2006). For instance, the rise of the relative cost of time increases the demand for the well-known national brands (Pashigian \& Bowen, 1994). From the viewpoint of the transaction costs theory, the impact of brand equity on consumer decisions increases in the case of product categories with high transaction costs (Fernández-Barcala \& GonzálezDíaz, 2006). Under the conditions of information asymmetry, the importance of a brand grows (Akerlof, 1970) since by its ability to signal quality the brand reduces information asymmetry, thus reducing search costs and perceived risk (Erdem \& Swait, 1998; Erdem et al., 2006; Christodoulides et al., 2006; Tsao et al., 2006).

1 After Research International has merged into TNS, this model was withdrawn from the market. 


\section{The Problem of Specification}

The debate on causal vs. reflective models is rather new; consequently, the problem of specification of brand equity models was never an issue in brand equity research, and the majority of models use reflective specification. The present paper operationalizes consumer-based brand equity in a causal measurement model.

When searching for the answer as to whether measure consumer-based brand equity with causal or reflective indicators, we do not want to answer the question what consumer-based brand equity is like. Consumer-based brand equity cannot be qualified as either reflective or causal in itself.

We consider that the theoretical and methodological arguments favour causal measurement.

The substantive theoretical formulations essential from the viewpoint of the causal specification of consumer-based brand equity are:

- Brand adds value to the product (Farquhar, 1989; Achenbaum, 1993).

- Consumer-based brand equity is the concept measuring the brand's ability to add value to a product.

- The totality of intangible brand assets (Aaker, 1991).

There are also empirical models that employ the causal specification of brand equity without arguing about the chosen specification (Yoo \& Donthu, 2000; Martensen \& Gronholdt, 2004; Jensen \& Klastrup, 2009; Netemeyer et al., 2004).

The methodology used determines the way we specify the concepts of our model. The first-order latent variables (the dimensions of brand equity) are causing the first-order CBBE. The study estimates the first-order latent variables (dimensions of the CBBE) in reflective measurement models.

In survey-based data collection, we measure latent concepts by asking the interviewees about brand-related associations already present in their mind. When the respondents answer questions related to benefits or perceived quality, their already existent ideas about the benefits and quality will manifest. In this case, the only suitable method for measuring consumer-based brand equity dimensions is measuring with reflective indicators.

Consumer-based brand equity is a theoretical term; thus, consumers do not have already existing ideas about this concept, and consequently CBBE can have no reflections. The substantive formulations essential from the viewpoint of the causal specification of consumer-based brand equity: brand adds value to the product (Farquhar, 1989; Achenbaum, 1993), brand equity is defined as the totality of intangible brand assets (Aaker, 1991). Consequently, theory regards brand equity as something that comes into being due to the associations linked to the brand name.

This study distinguishes causal models from composite (formative) as well as reflective models. To the proposal of Bollen (2011), we will try to avoid the 
use of the formative notion because it has often been used in the literature to denote (causal) measurement models with real latent variable and (composite) measurement models as well. There are important differences between these concepts. In the case of reflective models, the indicators are the reflections of the latent variable, while in the case of causal models the latent variable is determined by the indicators. In the case of composite (formative) measurement models, a composite (and not a latent) variable is determined by the indicators. In causal measurement, a disturbance term is estimated at the level of the latent variable, which is not the case in composite model estimation.

To estimate causal models with latent variable, estimators (maximum likelihood by default) assured by covariance-based software (Amos, EQS, Lisrel) are suitable, while a popular way to estimate the composite measurement models is PLS (Smart PLS).

The causal measurement model presumes the following relations:

Where $i^{\text {th }}$ is the causal indicator, the parameter measures the direct effect of the $i^{\text {th }}$ indicator on the latent variable, while the disturbance term comprises the variance not captured by the indicators (Diamantopoulos, Riefler, and Roth 2008). There is no correlation between the disturbance term and the indicators of the latent variable $(\operatorname{cov}()=0)$.

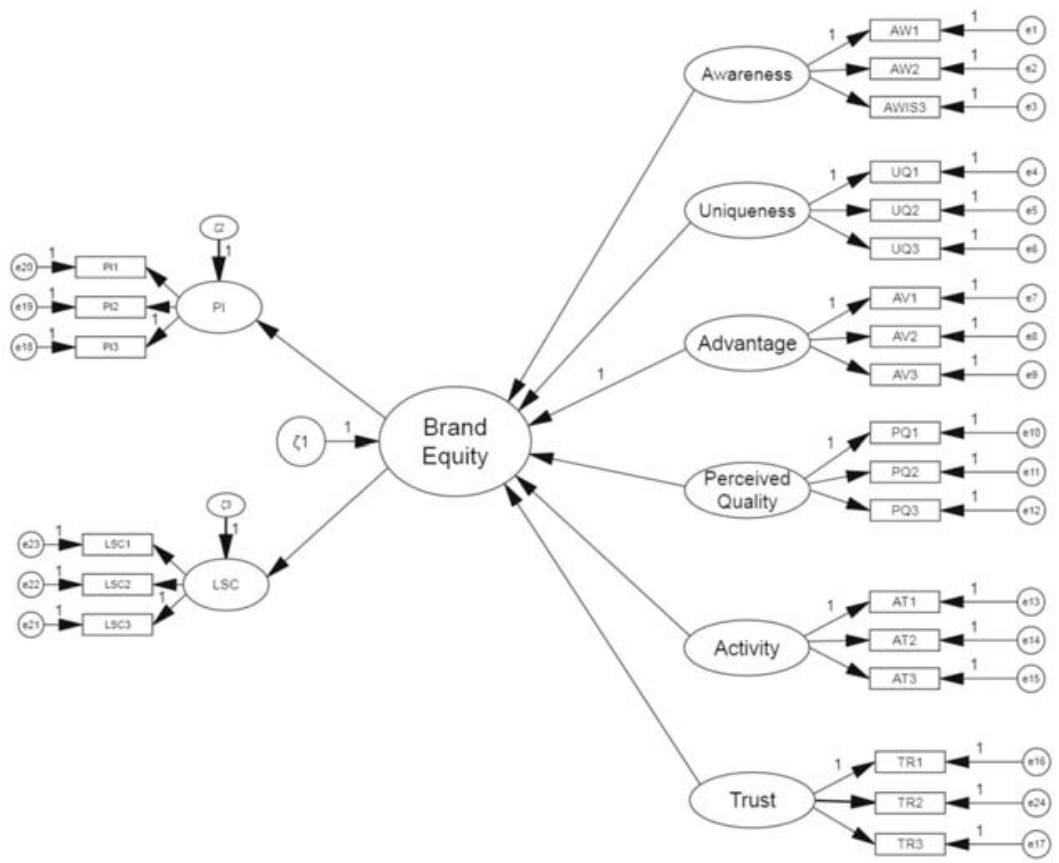

Source: own design

Figure 1. The initial model of the causally measured brand equity 
Illustrating brand equity within a structural equation gives us the opportunity to model consumer-based brand equity together with its sources and consequences. In the model above, the first-order latent variables freely correlate, but the covariance arrows are not represented. The six reflectively measured dimensions cause brand equity, which determines its two consequences: Purchase Intention (PI) and Low Search Cost (LS).

Some important considerations determine the conceptual development of this study. The consumer-based brand equity model has to be a useful tool for management, and brand equity dimensions have to be under the control of management. For example, coherent managerial decisions can build trust. Brand equity measure has to be independent from industry and valid at high abstraction level. It follows from the foregoing that measurement applies to corporate brands, umbrella brands, or product brands rather than on specific product models.

\section{Methodology}

Structural equation modelling makes possible the application of numerous analysis techniques together, which are built on the general linear model (GLM) (Ullman, 2006). Continuous and discrete independent variables as well as continuous and discrete dependent ones can be built into this model; at the same time, the observed as well as latent variables can also be included and their cause-effect relationships can also be analysed within the same model.

The model has two important parts: the measurement model and the structural model (Tomarken \& Waller, 2003). In strict terms, the measurement model is a confirmatory factor analysis model (Garson, 2011), in which the relationship between the latent variables and indicators (observed variables) are modelled and the goodness-of-fit is analysed. In fact, we do not make a further step in building a model until the validity of our measurement model is fulfilled. The measurement model evaluates convergent and discriminant validity, while the structural model assures the evaluation of the theoretical validity (Schumacker \& Lomax, 2010).

In structural equation modelling, we also have the possibility to analyse the goodness-of-fit of the two components: the measurement model and the path model separately. One of McDonald and Ho's (2002) most important methodological conclusions is that the goodness-of-fit of the structural equation model is not acceptable if the goodness-of-fit of the two component models is not fulfilled. More precisely, according to the two-step method suggested by them, a model can be regarded as acceptable if the measurement model is fitted first and the path model is fitted next. 


\subsection{Scale Development, Data Collection, and Sample}

Starting from the empirical research based on Aaker's $(1991,1996)$ model, empirical findings, and the initial model of this study, the authors generated a number of 66 scale items, adapting the majority of the items from other studies (Lehmann et al., 2008; Erdem \& Swait, 2006) and formulating some new ones.

The authors presumed that everyone is highly familiar with the selected mobile phone product category, and they selected three mobile phone brands (Nokia, Samsung, and iPhone) as stimuli, mostly because everybody has the possibility to easily get in contact with and experience several mobile phone brands, and consequently give more relevant answers about different brands. At the time of the data collection, the market leader was Nokia and the second biggest brand was Samsung. Despite the presumption that sample members have moderate knowledge or have no experience with iPhone, this brand also enters the study with the scope of testing the possibility of brand measurement when experience is low or is missing.

The questionnaire was carried out with the help of two online survey providers (SurveyMethods, Zoomerang). We sent questionnaires to 395 people's email box, but actually more people received them. The questionnaires were passed to the respondents in three forms. The preferred one was a link sent in a personalized electronic letter following which the addressee could fill in the questionnaire. For security reasons, we did not make it possible to fill in the questionnaire twice from a link sent out to an email. The second form of polling was sending a direct link to people who had agreed before to fill in the questionnaire. In this case, filling in the questionnaire was also limited to one computer, or more precisely only one questionnaire could be filled in from one IP address. The third form of polling was made personally. It was used mostly in the case of those people over forty or fifty who had agreed to fill in the questionnaire but balked at the electronic fill-in or the use of the Internet. The response rate in the case of the questionnaires sent to email addresses can be estimated to $60 \%$.

The analysis starts with 421 observations, coming from a Romanian quota sampling. During the analyses of the missing data, we eliminate the observations with more than $30 \%$ missing data, and as missing data does not qualify as MCAR (Missing Completely at Random) the author uses Direct ML estimation in Amos to impute $3.7 \%$ of missing data.

We used quota sampling based on gender and age. Data referring to the statistical population were downloaded from the data service provider (Tempo) of the National Institute of Statistics of Romania (www.insse.ro). After deleting outliers and observations with a large proportion of missing data, 332 observations were included into the sample, serving as a starting point for the analyses. But since we deleted the outliers and the observations with missing data earlier, the 
proportion of the 15-19 age category significantly decreased to such an extent that we should have used a quadruple factor in applying the weights. The decrease of this age-group in the sample is explained by the fact that in comparison to the other respondents understanding and answering the questions caused difficulties to its members. After deleting the 15-19-year-olds, our sample decreased to 315. Table 1 illustrates the distribution of the sample according to age and gender. Based on this distribution, we weighted our sample to match the distribution of the population.

Table 1.Weighting data according to gender and age

\begin{tabular}{ccc}
\hline Age & Gender & n \% \\
\hline $20-29$ & Man & 13.33 \\
\hline $20-29$ & Woman & 25.08 \\
\hline $30-39$ & Man & 13.29 \\
\hline $30-39$ & Woman & 23.73 \\
\hline $40-49$ & Man & 5.06 \\
\hline $40-49$ & Woman & 7.28 \\
\hline $50-59$ & Man & 6.96 \\
\hline $50-59$ & Woman & 5.06 \\
\hline Total & & 100 \\
\hline
\end{tabular}

Because weighted data files are not supported by Amos, we generated a correlation matrix of the measured variables of the model and used this matrix as an input for our structural model.

\subsection{Analyses}

The research design does not presume any experience of the interviewees with the specific brand but presupposes experience with the product category. In assessing a brand, consumers have two great sources to rely on: abstract information originating in the brand name and the one that relates to detailed product attributes (Dillon et al., 2001; Tafani et al., 2004; Betts \& Taran, 2004; Raggio \& Leone, 2006; Boatwright et al., 2008). This study considers experiencebased data best for building the model; consequently, the assessment of causal specification uses Nokia data (almost 60\% from the sample owns Nokia and 16.5\% has Nokia as a second mobile, against $16.9 \%$ of Samsung and $1.7 \%$ of iPhone). Multicollinearity is not likely to pose estimation problems as the maximum VIF (Variance Inflation Factor) value of measured variables is 3.68.

The first step in the search for the suitable causal specifications is the assessment of the measurement model. During this process, we drop several indicators from 
the analysis because of low weight, low significance, or low explained variance. Fit indicators of the six-factor CFA (Nokia) do not represent an impressive fit (TLI 0.83, CFI 0.85, RMSEA 0.101); after the elimination of the indicators of Awareness with unacceptably low weight $(0.29,0.48)$, the model fit got better (TLI 0.83, CFI 0.915, RMSEA 0.82).

The high correlation between Trust and Perceived Quality (0.95) indicates the lack of discriminant validity, suggesting that the two dimensions measure the same thing in fact. After an analysis of the problem, the study formulates the following conclusion. The respondents use their trust in quality as a proxy in order to answer the questions related to perceived quality; they are able to respond the quality-related questions only by quickly examining how much trust they feel in the brand as the questions of quality confuse them.

Despite the fact that Awareness is part of conceptual models, it does not enter the final model of this study. According to the conceptual definition, awareness refers directly to the node in the associative network that stores information related to the brand name. Awareness could not be seen as an association that is linked to the brand node, but something that indicates the presence of this brand node.

The low factor loadings and non-significant path estimates also suggest that the Awareness dimension has to be excluded from the model. Independent fit causes problems in some other researches (Yoo \& Donthu, 2001), while others exclude this dimension from the final model as well (Atilgan et al., 2009). The explanation of the phenomenon is that, owing to the great awareness of brand names, the variables get so biased (extreme skew and kurtosis) that fit with the help of ML is not possible.

Activity, a behavioural construct, is part of the initial model even though the conceptual requirements demand clear differentiation of attitudinal constructs from behavioural ones. The authors conceptualized the dimensions (antecedents) of the focal construct as attitudinal constructs and the consequences as behavioural constructs; consequently, the authors introduced the Activity dimension wrongly in the initial model. On the other hand, the Activity dimension has almost no explanatory power (standardized estimate: 0.04 ), and its effect on Brand equity is implicitly not significant; as a consequence, it has to be eliminated from the model.

Interpretation of the Uniqueness dimension at a high abstraction level proved to be problematic. For example, the statement that the Nokia brand is unique is difficult to interpret (as it has both really unique and everyday models). This could be one of the main reasons that the Uniqueness dimension has no significant explanatory power and its indicators do not load significantly onto a more general Differentiation construct either. For theoretical and methodological reasons, the authors also eliminated the indicators of Uniqueness.

As a final result, a two-dimensional model is accepted, in which the two dimensions of the consumer-based brand equity (Trust (in quality) and 
Advantage) determine the consumer-based brand equity, explaining more than $70 \%$ of variance; and consumer-based brand equity has a positive effect on its two consequences, namely purchase intention and low search cost.

\section{Results}

The model below (Figure 2) illustrates the final model. The two-dimensional structure will make measurement simple and economical, thus being an intuitive solution for management.

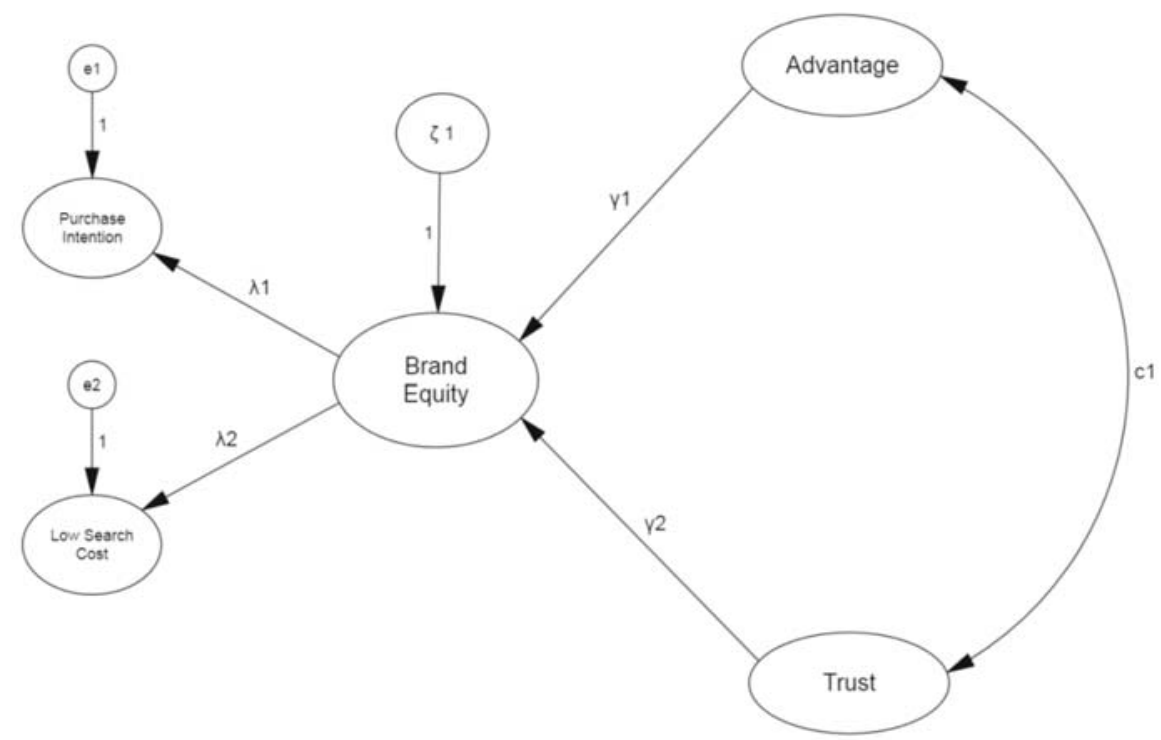

Source: own design

Figure 2. The model of the causally measured brand equity

Advantage and Trust (in quality) are exogenous variables; therefore, the model does not estimate error at their level and they are allowed to correlate freely. In the case of Purchase Intention and Low Search Cost, the model estimates the disturbance term which corresponds to the variance unexplained by Brand Equity as well as it also estimates measurement errors at the level of the indicators. The disturbance term at the brand equity level draws a clear picture of the extent to which the two dimensions explain the variance of the central concept. Table 2 provides results from the assessment of overall fit for the three mobile phone brands. In the case of Nokia, the goodness-of-fit indicators are excellent. The TLI and CFI exceed the conservative 0.95 boundary as well, the relative chi-square corresponds to the requirement that Hair et al. (2009) formulate, the RMSEA 
value is good, and SRMR qualifies as outstanding (0.034). In the case of the other two brands, the baseline comparison indices above the 0.9 cut-off value represent a good fit; only the RMSEA values indicate a lower fit in comparison to Nokia. In both cases (Samsung, iPhone), the 0.05 value of the SRMR also shows a good fit.

Table 2. Fit statistics

\begin{tabular}{lccccc}
\hline Goodness-of-fit & & & & & \\
\hline & $\chi^{2}$ & DF & TLI & CFI & RMSEA \\
\hline Nokia & 198 & 72 & 0.96 & 0.97 & 0.08 \\
\hline Samsung & 299 & 72 & 0.93 & 0.95 & 0.10 \\
\hline iPhone & 420 & 73 & 0.90 & 0.92 & 0.13 \\
\hline
\end{tabular}

Source: own estimations

The direct effects of indicators and latent variables are all significant. Since the data correspond to the univariate normality but not the multivariate normality assumption, it is important to check the validity of the model with the parametric bootstrap procedure, which is independent from the multivariate normality assumption (Schumacker \& Lomax, 2010). The significance and parameters of ML (Maximum Likelihood) estimation correspond to the significance levels and parameters of the parametric bootstrap procedure on a sample of 1,200 with a minimum difference. All these indicate that even in the absence of multivariate normality the study can accept the maximum likelihood estimates of the model. The low values (all well below 2.58) of the standardized residuum matrix affirm the excellent fit of our model as well.

\subsection{Assessment of Reliability and Validity of Measurement Models}

As the model operationalizes first-order latent variables in reflective measurement models, the assessment of reliability and validity is possible with the classical test theory. The assessment of reliability and validity (Table 3) follows Hair et al.'s (2009) indications, according to which the study uses four indicators in assessing the convergent validity.

Table 3. Convergent validity test

\begin{tabular}{|c|c|c|c|c|c|c|c|c|c|c|c|c|}
\hline & \multicolumn{4}{|c|}{ Nokia } & \multicolumn{4}{|c|}{ Samsung } & \multicolumn{4}{|c|}{ iPhone } \\
\hline & CR & AVE & SRW & SMC & CR & AVE & SRW & SMC & CR & AVE & SRW & SMC \\
\hline Advantage & 0.91 & 0.73 & & & 0.91 & 0.72 & & & 0.93 & 0.77 & & \\
\hline AV1 & & & 0.93 & 0.86 & & & 0.91 & 0.82 & & & 0.95 & 0.91 \\
\hline AV2 & & & 0.91 & 0.82 & & & 0.92 & 0.85 & & & 0.93 & 0.86 \\
\hline AV3 & & & 0.75 & 0.56 & & & 0.78 & 0.6 & & & 0.79 & 0.62 \\
\hline AV4 & & & 0.82 & 0.67 & & & 0.8 & 0.64 & & & 0.83 & 0.69 \\
\hline
\end{tabular}




\begin{tabular}{|c|c|c|c|c|c|c|c|c|c|c|c|c|}
\hline & \multicolumn{4}{|c|}{ Nokia } & \multicolumn{4}{|c|}{ Samsung } & \multicolumn{4}{|c|}{ iPhone } \\
\hline & CR & AVE & SRW & SMC & CR & AVE & SRW & SMC & CR & AVE & SRW & SMC \\
\hline Trust & 0.91 & 0.71 & & & 0.90 & 0.68 & & & 0.92 & 0.74 & & \\
\hline PQ1 & & & 0.79 & 0.63 & & & 0.81 & 0.59 & & & 0.82 & 0.67 \\
\hline PQ2 & & & 0.81 & 0.66 & & & 0.8 & 0.58 & & & 0.81 & 0.66 \\
\hline TR1 & & & 0.87 & 0.76 & & & 0.85 & 0.77 & & & 0.88 & 0.78 \\
\hline TR2 & & & 0.88 & 0.78 & & & 0.86 & 0.75 & & & 0.92 & 0.84 \\
\hline $\begin{array}{l}\text { Purchase } \\
\text { intention }\end{array}$ & 0.86 & 0.67 & & & 0.9 & 0.75 & & & 0.92 & 0.80 & & \\
\hline PI1 & & & 0.71 & 0.51 & & & 0.85 & 0.72 & & & 0.9 & 0.81 \\
\hline $\mathrm{PI} 2$ & & & 0.9 & 0.81 & & & 0.91 & 0.82 & & & 0.92 & 0.82 \\
\hline PI3 & & & 0.84 & 0.71 & & & 0.85 & 0.72 & & & 0.88 & 0.77 \\
\hline $\begin{array}{l}\text { Low search } \\
\text { cost }\end{array}$ & 0.92 & 0.79 & & & 0.95 & 0.86 & & & 0.92 & 0.81 & & \\
\hline LSC1 & & & 0.89 & 0.79 & & & 0.91 & 0.82 & & & 0.85 & 0.72 \\
\hline LSC2 & & & 0.9 & 0.81 & & & 0.94 & 0.88 & & & 0.92 & 0.85 \\
\hline LSC3 & & & 0.88 & 0.78 & & & 0.94 & 0.88 & & & 0.92 & 0.85 \\
\hline
\end{tabular}

The standardized regression weights (SRW) and the squared multiple correlations (SMC) measure the reliability and validity of indicators, whereas the composite reliability (CR) and average variance extracted (AVE) measure the reliability and validity of latent variables. Amos does not print in the output the latter two indicators, but we compute them based on the formulas from Hair et al. (2009). The squared multiple correlations for every indicator exceed the 0.5 value and the standardized coefficients all exceed the 0.7 value; all this indicates convergent validity. In the case of all four latent variables, the CR exceeds 0.7 and, similarly, the AVE exceeds 0.5, indicating that the variables of the model correctly map the contents of the dimensions.

The assessment of discriminant validity involves different methods. This study considers three of them: the AVE method, nested comparison test of CFA, and confidence intervals of correlation. The first approach compares the average variance extracted (AVE) of two constructs with shared variance measured with the square of the correlation between the two constructs (Fornell \& Larcker, 1981). If in the case of both variables AVE is greater than the shared variance, then discriminant validity is supported. The assessment of the Nokia and iPhone models provides support for discrimination as all AVE are greater than the shared variance. In the case of the Samsung brand, the dimensions of brand equity do not pass the AVE test, but they do pass the other two. The confidence intervals of correlations from the bootstrapping estimation prove that the correlation (.86) between Trust (in quality) and Advantage is significantly different from 1. The CFA comparison test indicates that two latent variables represent best the manifest variables in comparison with the one latent solution. 
The values of ECVI $(.398<.799)$ and AIC $(122.87<246.96)$ are evidently lower for the two-dimensional solution, indicating evidence of discriminant validity. From the perspective of the brand equity model, a less important problem is the lack of discriminant validity between the consequences of Nokia's brand equity. By including the consequences as composite variables, the problem disappears and the assessment of external validity offers another solution to this problem.

If the causal specification of brand equity is theoretically sound, then the model will fit with other consequences as well. Estimating with two other consequences, Loyalty and OBE (Overall Brand Equity, Yoo \& Donthu, 2000), the model remains stable, the indicators show excellent fit. In the case of the model variant with Low Search Cost and OBB as consequences, the differences between AVE values and shared variance provide evidence of discriminant validity in the case of every latent variable.

\subsection{Assessment of Reliability and Validity of Causal Relationships}

Validity assessment of causal measures is a controversial topic (Diamantopoulos et al., 2008). This study, contrary to skepticism related to the applicability of statistical procedures, stresses the importance of establishment of validity (Edwards \& Bagozzi, 2000). The study realizes an assessment of validity following the recommendations of Diamantopoulos et al. (2008) and Bollen (2011).

The present model determines the causal relationships at the level of structural relationships, as first-level latent variables causally determine second-level brand equity. The significant $\gamma$-s indicates the validity of the first-level causal measures (Advantage and Trust (in quality)) (Diamantopoulos et al., 2008; Bollen, 2011). Another test of validity is to examine overall fit (Bollen, 2011). Table 1 provides evidence for excellent fit for the Nokia brand.

For the assessment of external validity, Bollen (2011) suggests embedding the construct in a more complex model with a full set of relationships (determinants and consequences), thus finding the expected effects provide evidence for external validity. The positive sign of high values of path estimates (Figure 3) supports external validity for every model. Moreover, testing the model with other latent variables, as Loyalty and OBE, provides further evidence of external validity as the fit indices represent a very good fit $\left(\chi^{2}=244, \mathrm{df}=88\right.$, TLI=.955, CFI=.963, RMSEA=.075). Following certain recommendations of Diamantopoulos et al.

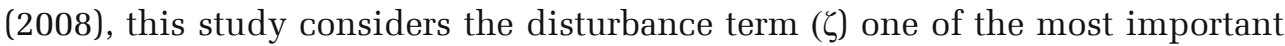
indicators of construct validity. The standardized value of the disturbance provides information about the variance explained. The two-dimensional structure is able to explain $70 \%$ of the brand equity; dimension variance in the case of the Nokia brand supports construct validity. 


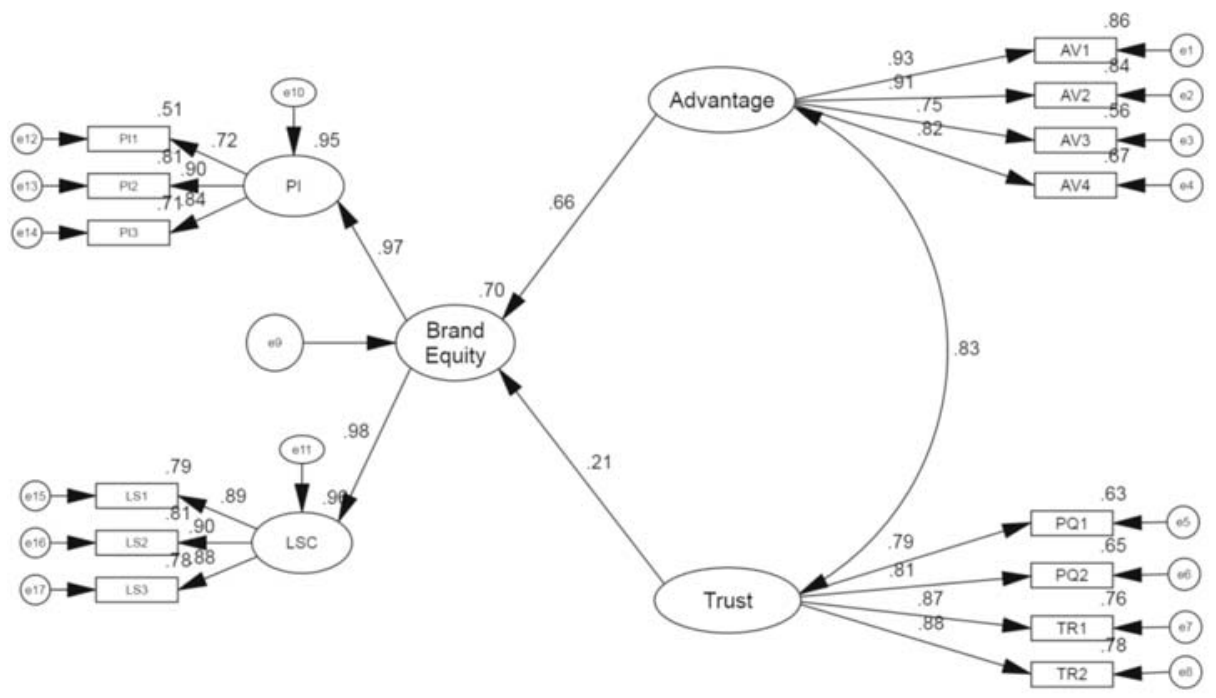

Source: own estimations

Figure 3. Standardized estimates of brand equity model (Nokia brand)

\section{Discussion}

\subsection{Conclusions}

This research answers the main question of the present study, namely, which are those brand-related concepts that can enter an associative structure where they are simultaneously causing something, with a two-dimensional model. The findings indicate that in this case only two concepts, namely trust in a brand and the advantages that a brand offers, can be built into a causal structural model.

The result of the present paper and other empirical results (Yoo \& Donthu, 2000; Netemeyer et al., 2004; Atilgan et al., 2009; Jensen \& Klastrup, 2009) propose a simpler structure.

Owing to the causal specification, this study finds both a theoretically and practically useful result. According to this result, consumer-based brand equity is a two-dimensional construct. Trust (in quality) in this context represents something that connects a consumer to a brand. In this sense, the Trust dimension contains the brand-related emotional element. Advantage is what a brand provides a consumer with; thus, this dimension represents the rational dimension of brand equity.

The study offers plausible theoretical and methodological arguments why awareness could not be included in a CBBE model. The authors consider that awareness actually refers directly to the node in the associative network that 
stores information related to the brand name; consequently, it cannot be regarded as an association.

Important empirical results confirm the simpler structure. In Netemeyer et al. (2004), the two dimensions of brand equity cause willingness to pay price premium. In the Yoo and Donthu (2000) model, if the authors correctly interpret loyalty as a consequence, this will also result in two dimensions; Jensen and Klastrup (2009) accept two models with four and three dimensions respectively. The present model starts in a different way; still, the final dimensions of the model resemble the dimensions of the mentioned studies. In Netemeyer et al. (2004), PQ/PVC (Perceived Quality/Perceived Value for the Cost) and Uniqueness together determine the willingness to pay premium price, while the credibility of a brand is one of the central elements of the Erdem and Swait (1998) model, one component of which is trust; Jensen and Klastrup (2008) accept two models and estimate one of them with the following three dimensions: Product Quality, Differentiation, Trust and Credibility.

This study manages to highlight an essential problem with the reflective specification of consumer-based brand equity. Using reflective specification, it makes possible to fit an even higher number of constructs into the model as they will share variance due to the halo effect and the common method. Consequently, a high number of consumer-based brand equity models can be built without knowing which are the dimensions capable of determining, causing something together. For example, in Lehman et al. (2008), the 27 constructs shared more than $60 \%$ of variance due to the common method bias.

\subsection{Limitations and Further Research}

The present research has some limitations. First of all, the sample is not randomly drawn, but the sample distribution of age and gender reflects the population distribution of these two variables.

The model is valid for one product category and a restricted number of brands, and it does not provide cultural validity.

The study considers every provided solution of the base brand (private label, fictive brand, weakest brand) comparison problematic. One cannot surely state that private labels do not have brand equity; in many industries, there are no private labels to use as base brand - it is hard to find an appropriate method for selecting the weakest brand. Using a fictive brand will result in irrelevant answers. As a consequence, the study does not deal with the base brand issue, but it considers testing the possibility of introducing the market leader brand as a base brand as a possible future research problem.

While devising the model, the study assumes that brand equity measurement is possible among non-users as well. However, on the basis of the respondents' answers 
and the experiences of assessment of fit, the study formulates the need for a certain degree of awareness and knowledge among respondents to assure model stability. Consequently, during data collection, the researcher should filter respondents to exclude those without knowledge and experience with the specific brand.

\section{Acknowledgements}

This work was supported by a grant of the Romanian Ministry of National Education, CNCS - UEFISCDI, project number PN-II-ID-PCE-2012-4-0066.

\section{References}

Aaker, D. A. (1989). Managing assets and skills: the key to a sustainable competitive advantage. California Management Review 31(2): 91-106.

(1991). Managing brand equity: Capitalizing on the value of a brand name. New York: Free Press.

(1996). Measuring brand equity across products and markets. California Management Review 38(3): 102-120.

Achenbaum, Alvin A. (1993). The mismanagement of brand equity. In: Lewis, Ian M. (ed.), ARF Fifth Annual Advertising and Promotion Workshop. Pennysilvania: The New York Hilton.

Agarwal, M. K.; Rao, V. R. (1996). An empirical comparison of consumer-based measures of brand equity. Marketing Letters 7(3): 237-247.

Ailawadi, K. L.; Lehman, D. R.; Neslin, S. (2003). Revenue premium as an outcome measure of brand equity. Journal of Marketing 67(4): 1-17.

Akerlof, G. A. (1970). The market for "lemons": quality uncertainty and the market mechanism. The Quarterly Journal of Economics 84(3): 488-500.

Atilgan, E.; Akinci, S.; Aksoy, S.; Kaynak, E. (2009), Customer-based brand equity for global brands: a multinational approach. Journal of Euromarketing 18(2): 115-132.

Baldauf, A.; Cravens, K. S.; Diamantopoulos, A.; Zeugner-Roth, K. P. (2009). The impact of product-country image and marketing efforts on retailer-perceived brand equity: an empirical analysis. Journal of Retailing 85(4): 437-452.

Bauer, A.; Berács, J. (2006). Marketing. Budapest: Aula.

Betts, S. C.; Taran, Z. (2004). The 'brand halo' effect on durable goods prices: brand reliability and the used car market. Academy of Marketing Studies Journal 8(1): 7-18.

Boatwright, P.; Ajay, K.; Zhang, W. (2008). Should consumers use the halo to form product evaluations. Management Science 54(1): 217-223. 
Bollen, K. (2011). Evaluating effect, composite, and causal indicators in structural equation models. MIS Quarterly 35(2): 359-372.

Boo, S.; Busser, J.; Baloglu, S. (2009). A model of customer-based brand equity and its application to multiple destinations. Tourism Management 30(2): 219-231.

Brand Asset Valuator, downloaded from: http://www.yrbav.com/, on: 02.25.2012.

BrandZ, downloaded from: http://www.wpp.com/wpp/marketing/brandz, on: 02.25.2012.

Chau, P.; Ho, C. (2008). Developing consumer-based service brand equity via the Internet: the role of personalization and triability. Journal of Organizational and Electronic Commerce 18(3): 197-223.

Chaudhuri, A.; Holbrook, M. B. (2001). The chain of effects from brand trust and brand affect to brand performance: the role of brand loyalty. Journal of Marketing 65(2): 81-93.

Christodoulides, G.; de Chernatony, L.; Furrer, O.; Shiu, E.; Abimola, T. (2006). Conceptualizing and measuring the equity of online brands. Journal of Marketing Management 22(7-8): 799-825.

Cobb-Walgren, C. J.; Beal C.; N. Donthu (1995). Brand equity, brand preferences, and purchase intent. Journal of Advertising 24(3): 25-40.

Delgado, E.; Munuera, J. L. (2005). Does brand trust matter to brand equity? Journal of Product and Brand Management 14(3): 187-196.

Delgado, E.; Munuera, J. L.; Yagüe, M. J. (2003). Development and validation of a brand trust scale. International Journal of Marketing Research 45(1): 35-54.

Diamantopoulos, A.; Riefler, P.; Roth, K. P. (2008). Advancing formative measurement models. Journal of Business Research 61(12): 1203-1218.

Dillon, W. R.; Madden, T. J.; Kirmani, A.; Mukherjee, S. (2001). Understanding what's in a brand rating: a model for assessing brand and attribute effects and their relationship to brand equity. Journal of Marketing Research 38(4): 415-430.

Edwards, J. R.; Bagozzi, R. (2000). On the nature and direction of relationships between constructs and measures. Psychological Methods 5(2): 155-174.

Erdem, T.; Swait, J. (1998). Brand equity as a signaling phenomenon. Journal of Consumer Psychology 7(2): 131-157.

Erdem, T.; Swait, J.; Valenzuela, A. (2006). Brands as signals: a cross-country validation study. Journal of Marketing 70(1): 34-49.

Farquhar, P. H. (1989). Managing brand equity. Marketing Research 1(3): 24-33.

Fornell, C.; Larcker, D. F. (1981). Evaluating structural equation models with unobservable variables and measurement error. Journal of Marketing Research 18(1): 39-50.

Garson, G. D. (2011). Structural equation modeling. Statnotes: topics in multivariate analysis. North Carolina State University, downloaded from: http://faculty.chass.ncsu.edu/garson/pa765/statnote.htm, on: 1/18/2011. 
Hair, J. F.; Anderson, R.; Tatham, R.; Black, W. (2009). Multivariate Data Analysis. New York: Prentice Hall.

Hooley, G.; Cox, T.; Fahy, J.; Shipley, D.; Berács, J.; Fonfara, K.; Snoj B. (2000), Market orientation in the transition economies of central Europe: tests of the Narver and Slater market orientation scales. Journal of Business Research 50(3): 273-285.

Hoyer, W. D. (1984). An examination of consumer decision making for common repeat purchase product. Journal of Consumer Research 11(3): 822-829.

Hoyer, W. D.; Brown, S. P. (1990). Effects of brand awareness on choice for a common, repeat purchase product. Journal of Consumer Research 17(2): 141-148.

Huang, R.; Sarigöllü, E. (2012). How brand awareness relates to market outcome, brand equity, and the marketing mix. Journal of Business Research 65(1): 92-99.

Jensen, M. B.; Klastrup, K. (2008). Towards a B2B customer-based brand equity model. Journal of Targeting, Measurement and Analysis for Marketing 16(2): 122-128.

Kapferer, J. N. (2008). The new Strategic brand management. London and Philadelphia: Kogan Page.

Keller, K. L. (1993) Conceptualizing, measuring, and managing customer-based brand equity. Journal of Marketing 57(1): 1-22.

Keller, K. L.; Lehmann, D. R. (2003). How do brands create value? Marketing Management 12(3): 26-31.

Kim, J.; Hyun, Y. J. (2010). A model to investigate the influence of marketingmix efforts and corporate image on brand equity in the IT software sector. Industrial Marketing Management 40(3): 424-438.

Laroche, M.; Kim, C.; Zhou, L. (1996). Brand familiarity and confidence as determinants of purchase intention: an empirical test in a multiple brand context. Journal of Business Research 37(2): 115-120.

Lehmann, D. R.; Keller, K. L.; Farley, J. U. (2008). The structure of survey-based brand metrics. Journal of International Marketing 16(4): 29-56.

Leong, S. M. (1993). Consumer decision making for common, repeat purchase products: a dual replication. Journal of Consumer Psychology 2(2): 193-208.

Macdonald, E.; Sharp B. (2000). Brand awareness effects on consumer decision making for a common, repeat purchase product: a replication. Journal of Business Research 48(1): 5-15.

Martensen, A.; Gronholdt, L. (2004). Building brand equity: a customer-based modeling approach. Journal of Management Systems 16(3): 37-51.

McDonald, R. P.; Ho, M. R. (2002). Principles and practice in reporting structural equation analyses. Psychological Methods 7(1): 64-82.

Netemeyer, R. G.; Krishnan, B.; Pullig, C.; Wang, G.; Yagci, M.; Dean, D.; Ricks, J.; Wirth, F. (2004). Developing and validating measures of facets of customerbased brand equity. Journal of Business Research 57(2): 209-224. 
Pashigian, B. P.; Bowen, B. (1994). The rising cost of time of females, the growth of national brands, and the supply of retail services. Economic Inquiry 32(1): 33-65.

Patterson, A. (2012). Social-networkers of the world, unite and take over: a metaintrospective perspective on the Facebook brand. Journal of Business Research 65(4): 527-534.

Peres, R.; Muller, E.; Mahajan V. (2010). Innovation diffusion and new product growth models: A critical review and research directions. International Journal of Research in Marketing 27(2): 91-106.

Raggio, R. D.; Leone, R. P. (2006). The theoretical separation of brand equity and brand value: managerial implications for strategic planning. Journal of Brand Management 14(5): 380-395.

Ramello, G. (2006). What's in a sign? Trademark law and economic theory. Journal of Economic Surveys 20(4): 547-565.

Schumacker, R. E.; Lomax, R. G. (2010). A beginner's guide to structural Equation modeling. Mahwah: Lawrence Erlbaum Associates.

Sengupta, A.; Greetham, D. V. (2010). Dynamics of brand competition: effects of unobserved social networks. Journal of Economic Dynamics and Control 34(12): 2391-2406.

Sharp, B.; Dawes, J. (2001). What is differentiation and how does it work. Journal of Marketing Management 17(7-8): 739-759.

Srinivasan, V.; Park, C. Su; Chang, D. R. (2005). An approach to the measurement, analysis, and prediction of brand equity and its sources. Management Science 51(9): 1433-1448.

Tomarken, A. J.; Waller, N. G. (2003). Potential problems with "well-fitting" models. Journal of Abnormal Psychology 112(4): 578-598.

Tsao, H.; Pitt, L. F.; Berthon, P. (2006). An experimental study of brand signal quality of products in an asymmetric information environment. Omega: The International Journal of Management Science. 34(4): 397-405.

Ullman, J. B. (2006). Structural equation modeling: reviewing the basics and moving forward. Journal of Personality Assessment 87(1): 35-50.

Washburn, J. H.; Plank, R. E. (2002). Measuring brand equity: an evaluation of a consumer-based brand equity scale. Journal of Marketing Theory and Practice 10(1): 46-62.

Yoo, B.; Donthu, N. (1997). Developing and validating a consumer-based overall brand equity scale for Americans and Koreans: an extension of Aaker's and Keller's conceptualizations. Paper Presented at AMA Summer Educators Conference, Chicago.

(2000). Developing and validating a multidimensional consumer-based brand equity scale. Journal of Business Research 52(1): 1-14. 